\title{
Maternal Anthropometric measurements, Pre-pregnancy Body Mass Index, and Fetal Growth Parameters - A Rural Experience
}

\author{
Surekha Tayade, Ritu Singh*, Jaya Kore, Neha Gangane \\ Department of Obstetrics and Gynecology, Mahatma Gandhi Institute of Medical Sciences, Sewagram, Wardha, \\ Maharashtra, India
}

*Corresponding Author: Ritu Singh, Department of Obstetrics and Gynecology, Mahatma Gandhi Institute of Medical Sciences, Sewagram, Wardha, Maharashtra, India, Tel: 7887519832; E-mail: ritusingh@mgims.ac.in

Received: 17 April 2018; Accepted: 30 April 2018; Published: 01 May 2018

\section{Abstract}

Background: Low pre-pregnancy BMI is considered a marker for minimal nutrient reserves, fetal growth restriction and adverse pregnancy outcome. This study was conducted to evaluate the influence of pre pregnancy BMI on fetal growth parameters.

Methods: A hospital based, cross-sectional, observational study was conducted among pregnant women seeking antenatal care at Kasturba Hospital, Sewagram, a rural institute in central India. Maternal pre-pregnancy BMI was calculated and correlated with new born birth weight, birth length, chest circumference, head circumference, arm circumference and ponderal index.

Results: Among 500 pregnant women of first trimester, the maternal mean Pre-pregnancy weight, height and Prepregnancy BMI were $47 \pm 5.77 \mathrm{~kg}, 154.43 \pm 5.39 \mathrm{~cm}$ and $19.78 \pm 2.56 \mathrm{~kg} / \mathrm{m}^{2}$ respectively. The mean Pre-pregnancy BMI in the LBW group was $19.25 \pm 1.68 \mathrm{~kg}$ as compared to $19.98 \pm 2.60 \mathrm{~kg}$ in normal birth weight group with a statistically significant difference $(\mathrm{z}=3.75, \mathrm{P}=0.001, \mathrm{z}=25.15, \mathrm{P}=0.000)$. Positive correlation was found between pre pregnancy maternal weight, and BMI with neonatal weight, neonatal length, chest circumference, head circumference and arm circumference. The association was negative with neonatal ponderal index. Mean neonatal length, ponderal index, chest circumference, head circumference a mid-arm circumference were statistically significantly associated with pre-pregnancy $\quad \mathrm{BMI} . \quad(\mathrm{F}=3.797 \quad \mathrm{P}=0.010 ; \quad \mathrm{F}=10.623 \quad \mathrm{P}=0.0001 ; \quad \mathrm{F}=18.924$ $\mathrm{P}=0.001 ; \mathrm{F}=3.948 \mathrm{P}=0.0001 ; \mathrm{F}=3.478, \mathrm{P}=0.016$ respectively). 
Conclusions: Women in the geographic region of the study had low body mass index depicting chronic malnourishment. BMI below $19.5 \mathrm{~kg} / \mathrm{m}^{2}$ and above $25 \mathrm{~kg} / \mathrm{m}^{2}$ were good predictors of low birth weight babies and had significant association with birth weight, length, head circumference, arm circumference and chest circumference.

Keywords: Maternal pre-pregnancy BMI; Pregnant women; Fetal growth parameters; Maternal anthropometry

\section{Introduction}

The most suitable objective anthropometric indicator of nutritional status of the adult is Body mass Index (BMI). This anthropometric indicator, derived from measures of weight and height of individuals, is consistently and highly correlated with body weight (or energy stores within the body) and is relatively independent of the height of the adult [1]. Data on BMI are relatively easy to collect and inexpensive to analyse. BMI, defined as weight in $\mathrm{kg}$ divided by height in meters squared [weight/(height) ${ }^{2}$ ], is still considered a simple, useful index for evaluating prepregnancy nutritional status in clinical settings ]. The Institute of Medicine (IOM) modified the body mass index (BMI) categories formulated in 1990 (underweight, $<19.8 \mathrm{~kg} / \mathrm{m}^{2}$; normal weight, $19.8-26 \mathrm{~kg} / \mathrm{m}^{2}$; overweight, $>26-$ $29 \mathrm{~kg} / \mathrm{m}^{2}$; obese, $>29 \mathrm{~kg} / \mathrm{m}^{2}$ ), to correspond to the 2009 World Health Organization classification (underweight, $<18.5 \mathrm{~kg} / \mathrm{m}^{2}$; normal weight, $18.5-24.9 \mathrm{~kg} / \mathrm{m}^{2}$; overweight, $25-29.9 \mathrm{~kg} / \mathrm{m}^{2}$; obese, $\geq 30 \mathrm{~kg} / \mathrm{m}^{2}$ ) and further recommended BMI-based weight gain during pregnancy [3]. Pre-pregnancy BMI is reportedly associated with pregnancy outcomes as an independent factor $[4,5]$ Low pre-pregnancy BMI is considered a marker for minimal nutrient reserves, fetal growth restriction and adverse pregnancy outcome [6]. The present study was conducted to evaluate the influence of maternal height, weight and pre pregnancy BMI on fetal growth parameters (fetal weight, length, ponderal index, chest circumference, head circumference and arm circumference) at birth.

\section{Methods}

After ethical approval and written consent from participants a hospital based prospective observational study was carried out in the department of Obstetrics and Gynecology of Mahatma Gandhi Institute of Medical Sciences, Sevagram, a rural based tertiary care hospital in eastern Maharashtra in central India. Pregnant women in the first trimester, amenable for follow up, who visited the outpatient department (OPD) or who were admitted in the maternity wards of the study site were recruited. over a period of 24 months $\left(1^{\text {st }}\right.$ December 2012 to $30^{\text {th }}$ November 2014). 500 consecutive, consenting pregnant women, regardless of age and parity, having singleton pregnancy participated. Detailed history was taken regarding socio-demographic characteristics like age, area of residence, gravidity, parity, booking status, literacy and socioeconomic condition. Maternal pre-pregnancy weight were recorded during her first antenatal visit in first trimester in kilograms on single, digital weighing machine. The woman was allowed to stand barefoot and motionless on the scale and weight was recorded to the nearest $100 \mathrm{gm}$. Zero error was checked for and removed every time if present. During the first 13 weeks of gestation a weight gain of around $1.7 \%$ can be assumed [7]. Thus, $250 \mathrm{gm}$ was subtracted from the weight measured in first trimester to obtain the recording of pre pregnancy weight (PPW). 
Height in meters was recorded with the individual standing on plain ground against a straight wall. The investigators standing to the left held the subject's chin with his/her left hand and the occiput with right little finger in the Frankfurt horizontal plane (an imaginary line joining the tragus of the ear to the eye). A hard quadrangular board was place over the head of subject and touching the wall. The level was marked with pencil and distance from ground was measured by nonstretchable tape with nearest $0.1 \mathrm{~cm}$.

Body mass index was calculated by the equation: Weight in $\mathrm{kg}$ / height in meters squared. BMI categories were defined according to WHO Classification (Table 1).

\begin{tabular}{|l|l|}
\hline Prepregnancy Weight & BMI kg/m ${ }^{2}$ \\
\hline Underweight & $<18.5$ \\
\hline Normal weight & $18.5-24.9$ \\
\hline Overweight & $25.0-29.9$ \\
\hline Obese & $\geq 30$ \\
\hline
\end{tabular}

Table 1: WHO classification for BMI $[8,9]$.

Further antenatal monitoring of the woman was done as per standard protocol without any interference from the research study. Planning and advice of pregnancy and any interventions took place as per the consultant who was looking after the woman and her pregnancy.

Newborn resuscitation and care was looked after by Paediatrician and adverse events if any were recorded. The naked baby was placed on an electronic weighing machine and birth weight was measured to the nearest 10 gram. Birth length, chest circumference, head circumference and arm circumference were measured in $\mathrm{cm}$ by using measuring tape. Ponderal Index was calculated by the formula,

$\mathrm{PI}=[$ weight (in g) $\mathrm{x} 100] \div[$ length $($ in $\mathrm{cm})$.

The data was entered in a spread sheet (Excel). Statistical analysis was done by using Descriptive and Inferential statistics using chi-square test, z-test, one-way ANOVA and multiple logistic regression analysis. The soft- wares used in the analysis were SPSS 17.0 version and Graph Pad Prism 5.0. The proportions were compared by chi square test. Multivariate logistic regression models were used to find out independent association of prognostic factors. A two-level $\mathrm{P}$ value $<0.05$ was considered as statistically significant. 


\section{Results}

The present hospital based prospective observational study was done in a rural based tertiary level institute. A total of 574 singleton pregnant women in first trimester, after fulfilling inclusion and exclusion criteria were enrolled for the present study of which $481(83.9 \%)$ came for follow up on their own and $19(3.3 \%)$ turned for final follow up after personal phone call and home visit by auxillary nurse midwife (ANM). Thus, data of 500 study participants could be finally analysed. An overview of the data showed that there was no macrosomic baby (Birth weight more than 4000 grams) in the study. The magnitude of low birth weight (LBW) babies was seen to be high. Thus, after initial descriptive statistics, study participants were grouped into those giving birth to low birth weight babies (below $2500 \mathrm{gm}$ ) and normal weight babies (above $2500 \mathrm{gm}$ ) for inferential statistics [9].

The maternal mean Pre-pregnancy weight, height and Pre-pregnancy BMI were $47 \pm 5.77 \mathrm{~kg}, 154.43 \pm 5.39 \mathrm{~cm}$ and $19.78 \pm 2.56 \mathrm{~kg} / \mathrm{m}^{2}$ respectively (Table 2). The mean pre-pregnancy weight in the LBW group was $45.52 \pm 3.90 \mathrm{~kg}$ as compared to $47.57 \pm 5.60 \mathrm{~kg}$ in normal birth weight group with a statistical significant difference ( $\mathrm{P}$ value $=0.0001$ ). The mean height in LBW was $153.84 \pm 4.72 \mathrm{~cm}$, whereas in the normal birth weight group it was $154.71 \pm 5.67 \mathrm{~cm}$. By using $Z$ - test statistically no difference was found in maternal height in both the groups $(\mathrm{Z}=1.685, \mathrm{P}=0.093)$. The mean Pre-pregnancy BMI in the LBW group was $19.25 \pm 1.68 \mathrm{~kg}$ as compared to $19.98 \pm 2.60 \mathrm{~kg}$ in normal birth weight group with a statistically significant difference ( $\mathrm{z}=3.75, \mathrm{P}=0.001, \mathrm{z}=25.15, \mathrm{P}=0.000$ ) (Table 3 ). Among Low birth weight group, by using Pearson correlation coefficient, positive correlation was found between pre pregnancy maternal weight, BMI with neonatal weight, neonatal length, chest circumference, head circumference and arm circumference. The association was negative with neonatal ponderal index (Table 4).

\begin{tabular}{|l|l|l|l|l|l|}
\hline Parameters & N & Minimum & Maximum & Mean & SD \\
\hline Pre-pregnancy Weight $(\mathrm{kg})$ & 500 & 32.00 & 92.00 & 47.00 & 5.77 \\
\hline Height $(\mathrm{cm})$ & 500 & 125.00 & 165.00 & 154.43 & 5.39 \\
\hline Pre-pregnancy BMI $\left(\mathrm{kg} / \mathrm{m}^{2}\right)$ & 500 & 13.50 & 37.80 & 19.78 & 2.56 \\
\hline
\end{tabular}

Table 2: Descriptive statistics for various parameters in study population.

\begin{tabular}{|c|c|c|c|c|c|}
\hline Parameters & $\begin{array}{l}\text { LBW Group } \\
(n=162)\end{array}$ & $\begin{array}{l}\text { Normal birth weight } \\
\text { Group }(n=338)\end{array}$ & Difference & Z-value & P-value \\
\hline $\begin{array}{l}\text { Pre-pregnancy } \\
\text { Maternal Weight }(\mathrm{kg})\end{array}$ & $45.52 \pm 3.90$ & $47.57 \pm 5.60$ & $2.04 \pm 0.43$ & 4.73 & $\begin{array}{l}0.0001 \\
\mathrm{~S}, \mathrm{p}<0.05\end{array}$ \\
\hline Maternal Height $(\mathrm{cm})$ & $153.84 \pm 4.72$ & $154.71 \pm 5.67$ & $0.86 \pm 0.51$ & 1.68 & $\begin{array}{l}0.093 \\
\mathrm{NS}, \mathrm{p}>0.05\end{array}$ \\
\hline $\begin{array}{l}\text { Pre-pregnancy } \\
\operatorname{BMI}\left(\mathrm{kg} / \mathrm{m}^{2}\right)\end{array}$ & $19.25 \pm 1.68$ & $19.98 \pm 2.60$ & $0.72 \pm 0.19$ & 3.75 & $\begin{array}{l}0.001 \mathrm{~S} \\
\mathrm{p}<0.05\end{array}$ \\
\hline
\end{tabular}

Table 3: Comparison of maternal anthropometric measures in low birth weight and normal birth weight group. 


\begin{tabular}{|l|l|l|l|}
\hline Variables & $\begin{array}{l}\text { Maternal Weight } \\
\text { Pre-pregnancy (r) }\end{array}$ & Maternal Height (r) & $\begin{array}{l}\text { Maternal BMI } \\
\text { pre-pregnancy(r) }\end{array}$ \\
\hline Birth Weight & 0.039 & $-0.236^{*}$ & $0.232^{*}$ \\
\hline Neonatal Length & $0.195^{*}$ & 0.019 & $0.174^{*}$ \\
\hline Neonatal PI & -0.209 & $-0.166^{*}$ & -0.065 \\
\hline Neonatal Chest Circumference & $0.250^{*}$ & 0.105 & $0.169^{*}$ \\
\hline Neonatal Head Circumference & $0.226^{*}$ & -0.004 & $0.233^{*}$ \\
\hline Neonatal Arm Circumference & $0.283^{*}$ & 0.041 & $0.262^{*}$ \\
\hline
\end{tabular}

$(\mathrm{r})=$ Pearson Correlation Coefficient, ${ }^{*}$ relation is statistically significant - means negative correlation

Table 4: Correlation between significant maternal and neonatal variables in low birth weight group ( $\mathrm{n}=162)$.

Maternal height was found to be positively correlated with neonatal length, chest circumference and arm circumference and negatively with neonatal head circumference, but significantly negative with neonatal weight and neonatal ponderal index (Table 4).

In normal birth weight group, of total 338 patients whose birth weight was $>2500$ gm, by using Pearson correlation coefficient, positive correlation was found between pre pregnancy maternal weight and BMI with neonatal weight, neonatal length, neonatal ponderal index, chest circumference, head circumference and arm circumference. The association was negative with arm circumference (Table 5). Whereas maternal height was negatively correlated with birth weight, neonatal length, ponderal index, chest circumference, arm circumference and neonatal albumin. The correlation was positive with head circumference (Table 5).

\begin{tabular}{|l|l|l|l|}
\hline Variables & $\begin{array}{l}\text { Maternal Weight Pre- } \\
\text { pregnancy (r) }\end{array}$ & $\begin{array}{l}\text { Maternal Height } \\
(\mathbf{r})\end{array}$ & $\begin{array}{l}\text { Pre-pregnancy } \\
\text { Maternal BMI (r) }\end{array}$ \\
\hline Birth Weight & $0.364^{*}$ & -0.102 & $0.402^{*}$ \\
\hline Neonatal Length & $0.136^{*}$ & $-0.272^{*}$ & $0.307^{*}$ \\
\hline Neonatal PI & $0.343^{*}$ & -0.030 & $0.337^{*}$ \\
\hline Neonatal Chest Circumference & 0.082 & $-0.343^{*}$ & $0.339^{*}$ \\
\hline Neonatal Head Circumference & $0.164^{*}$ & 0.007 & $0.163^{*}$ \\
\hline Neonatal Arm Circumference & $-0.137^{*}$ & -0.077 & -0.091 \\
\hline
\end{tabular}

$(\mathrm{r})=$ Pearson Correlation Coefficient, ${ }^{*}$ relation is statistically significant - means negative correlation.

Table 5: Correlation between significant maternal and neonatal variables in normal birth weight group $(\mathrm{n}=338)$. 
Out of total 500 women, 371 (74.2\%) had pre-pregnancy BMI between 18.5-24.9kg/m², $113(22.6 \%)$ had BMI $<18.5 \mathrm{~kg} / \mathrm{m}^{2}, 8(1.6 \%)$ had BMI between $25-29.9 \mathrm{~kg} / \mathrm{m}^{2}$ and8 $(1.6 \%) \geq 30 \mathrm{~kg} / \mathrm{m}^{2}$ (Table 6). Mean birth weight with mothers having BMI $<18.5 \mathrm{~kg} / \mathrm{m}^{2}$ was $2543.11 \pm 387.84 \mathrm{gm}, 2635.24 \pm 365.77 \mathrm{gm}$ for BMI between $18.5-24.9$ $\mathrm{kg} / \mathrm{m}^{2}, 3466.80 \pm 310.92 \mathrm{gm}$ for BMI between $25-29.9 \mathrm{Kg} / \mathrm{m}^{2}$ and $3055 \pm 334.11 \mathrm{gm}$ for BMI $\geq 30 \mathrm{Kg} / \mathrm{m}^{2}$. By using one way ANOVA, statistically significant association was found between neonatal weight and pre-pregnancy weight $(\mathrm{F}=21.785, \mathrm{p}=0.00)$. Mean neonatal length, ponderal index, chest circumference, head circumference a mid-arm circumference were statistically significantly associated with pre-pregnancy $\mathrm{BMI}$. $(\mathrm{F}=3.797 \mathrm{P}=0.010, \mathrm{~F}=10.623$ $\mathrm{P}=0.000, \mathrm{~F}=18.924 \mathrm{P}=0.00, \mathrm{~F}=3.948 \mathrm{P}=0.000, \mathrm{~F}=3.478, \mathrm{P}=0.016$ respectively) by applying one way ANOVA test (Table 6 and Graph 1).

\begin{tabular}{|c|c|c|c|c|c|c|}
\hline $\begin{array}{l}\text { Pre- pregnancy } \\
\operatorname{BMI}\left(\mathrm{kg} / \mathrm{m}^{2}\right)\end{array}$ & $\begin{array}{l}<18.5 \\
(\mathrm{n}=113)\end{array}$ & $\begin{array}{l}18.5-24.9 \\
(n=371)\end{array}$ & $\begin{array}{l}25-29.9 \\
(n=8)\end{array}$ & $\begin{array}{l}\geq 30 \\
(n=8)\end{array}$ & $\begin{array}{l}\text { F- } \\
\text { value }\end{array}$ & p-value \\
\hline $\begin{array}{l}\text { Birth Weight } \\
\text { (gm) }\end{array}$ & $2543.11 \pm 387.84$ & $2635.24 \pm 365.77$ & $3466.80 \pm 310.92$ & $3055 \pm 34.11$ & 21.785 & $\begin{array}{l}0.0001 \mathrm{~S}, \\
\mathrm{p}<0.05\end{array}$ \\
\hline $\begin{array}{l}\text { Neonatal Length } \\
(\mathrm{cm})\end{array}$ & $44.96 \pm 3.11$ & $45.41 \pm 1.40$ & $46.60 \pm 0.51$ & $46.50 \pm 0.54$ & 3.797 & $\begin{array}{l}0.010 \mathrm{~S}, \\
\mathrm{p}<0.05\end{array}$ \\
\hline $\begin{array}{l}\text { Ponderal Index } \\
\left(\mathrm{gm} / \mathrm{cm}^{3}\right)\end{array}$ & $27.62 \pm 5.20$ & $27.49 \pm 2.94$ & $33.70 \pm 3.05$ & $30 \pm 2.19$ & 10.623 & $\begin{array}{l}0.000 \mathrm{~S} \\
\mathrm{p}<0.05\end{array}$ \\
\hline $\begin{array}{l}\text { Chest Circumference } \\
(\mathrm{cm})\end{array}$ & $32.28 \pm 2.11$ & $32.74 \pm 1.03$ & $33.40 \pm 0.96$ & $36.50 \pm 3.83$ & 18.924 & $\begin{array}{l}0.000 \mathrm{~S}, \\
\mathrm{p}<0.05\end{array}$ \\
\hline $\begin{array}{l}\text { Head Circumference } \\
(\mathrm{cm})\end{array}$ & $33.21 \pm 2.42$ & $33.54 \pm 0.95$ & $34.40 \pm 0.96$ & $34.50 \pm 0.54$ & 3.948 & $\begin{array}{l}0.008 \mathrm{~S} \\
\mathrm{p}<0.05\end{array}$ \\
\hline $\begin{array}{l}\text { Arm Circumference } \\
(\mathrm{cm})\end{array}$ & $17.11 \pm 21.08$ & $13.64 \pm 1.20$ & $13.70 \pm 1.25$ & $13.50 \pm 0.54$ & 3.478 & $\begin{array}{l}0.016 \mathrm{~S}, \\
\mathrm{p}<0.05\end{array}$ \\
\hline
\end{tabular}

Table 6: Correlation of Pre- pregnancy BMI with neonatal parameters.

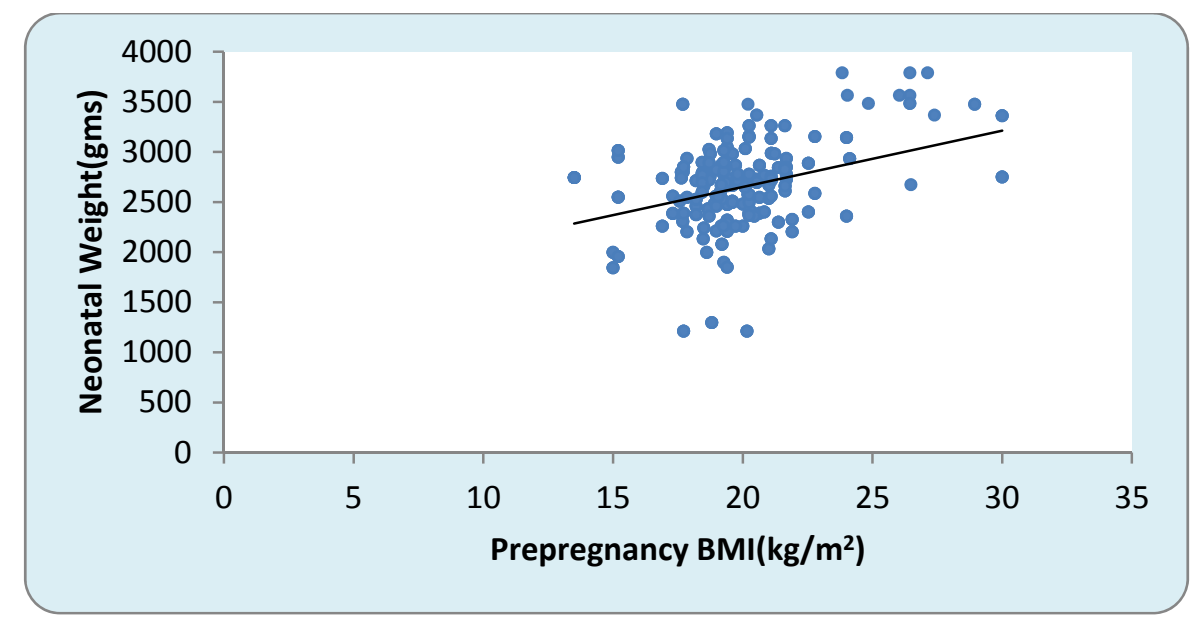

Graph 1: Correlation between pre-pregnancy BMI and Birth weight $\mathrm{kg})(\mathrm{n}=500)$. 
Multiple regression analysis showed that pre - pregnancy weight is significantly associated with low birth weight. The adjusted odds ratio for developing LBW decreases significantly with increasing pre- pregnancy weight. This is not true with pre-pregnancy BMI (Table 7).

\begin{tabular}{|c|c|c|c|c|c|}
\hline \multirow[t]{2}{*}{ Variables } & \multicolumn{2}{|c|}{$\begin{array}{l}\text { Unstandardized } \\
\text { Coefficients }\end{array}$} & \multirow[t]{2}{*}{ p-value } & \multicolumn{2}{|c|}{$\begin{array}{l}\text { 95.0\% Confidence Interval for } \\
\text { B }\end{array}$} \\
\hline & B & Std. Error & & Lower Bound & Upper Bound \\
\hline Pre-pregnancy Weight & 0.017 & 0.006 & $0.004 \mathrm{~S}, \mathrm{p}<0.05$ & 0.006 & 0.028 \\
\hline Pre pregnancy BMI & 0.002 & 0.012 & $0.862 \mathrm{NS}, \mathrm{p}>0.05$ & -0.022 & 0.026 \\
\hline
\end{tabular}

Table 7: Multiple Regression Analysis.

Maternal height $<150 \mathrm{~cm}$ had a sensitivity of $16.67 \%$, specificity of $82.23 \%$, positive predictive value of $67.31 \%$, negative predictive value of $67.31 \%$ and likelihood ratio of 0.93 in prediction of LBW babies. Maternal prepregnancy weight had a high sensitivity of $92.59 \%$ and negative predictive value of $88.12 \%$ with a likelihood ratio of 1.25 for LBW babies, however specificity was low. Maternal BMI above $25 \mathrm{~kg} / \mathrm{m}^{2}$ had $100 \%$ sensitivity and $100 \%$ NPV in detecting LBW babies with a likelihood ratio of 1.05 (Table 8 and Graph 2).

When sensitivity and specificity at each point was calculated as in pre pregnancy weight $<35,<40,<45,<50,<55$, $<60,<65 \mathrm{~kg}$, it was found that as the weight of women increases sensitivity of detection of low birth weight increases and specificity decreases (Graph 3). And at one point it meets which is designated as values at the point of interaction. This is the cut-off point above which sensitivity is maximum and below which specificity is maximum. Cut off point in pre pregnancy weight was $<45 \mathrm{~kg}$, and pre-pregnancy BMI was $19.5 \mathrm{Kg} / \mathrm{m}^{2}$ (Graph 4).

\begin{tabular}{|l|l|l|l|l|l|}
\hline Predictive ability & Sensitivity\% & Specificity\% & PPV \% & NPV \% & $\begin{array}{l}\text { Likelihood } \\
\text { Ratio }\end{array}$ \\
\hline Maternal Height $(<150 \mathrm{~cm})$ & & & & & 0.93 \\
\hline Pre-pregnancy Maternal Weight $-(<50 \mathrm{~kg})$ & 92.59 & 26.33 & 37.59 & 88.12 & 1.25 \\
\hline Pre-pregnancy BMI $\left(<18.5 \mathrm{~kg} / \mathrm{m}^{2}\right)$ & 25.31 & 78.70 & 36.28 & 68.73 & 1.18 \\
\hline Pre-pregnancy BMI $\left(>25 \mathrm{~kg} / \mathrm{m}^{2}\right)$ & 100 & 47.34 & 33.47 & 100 & 1.05 \\
\hline
\end{tabular}

Table 8: Predictive ability of maternal anthropometric measures. 


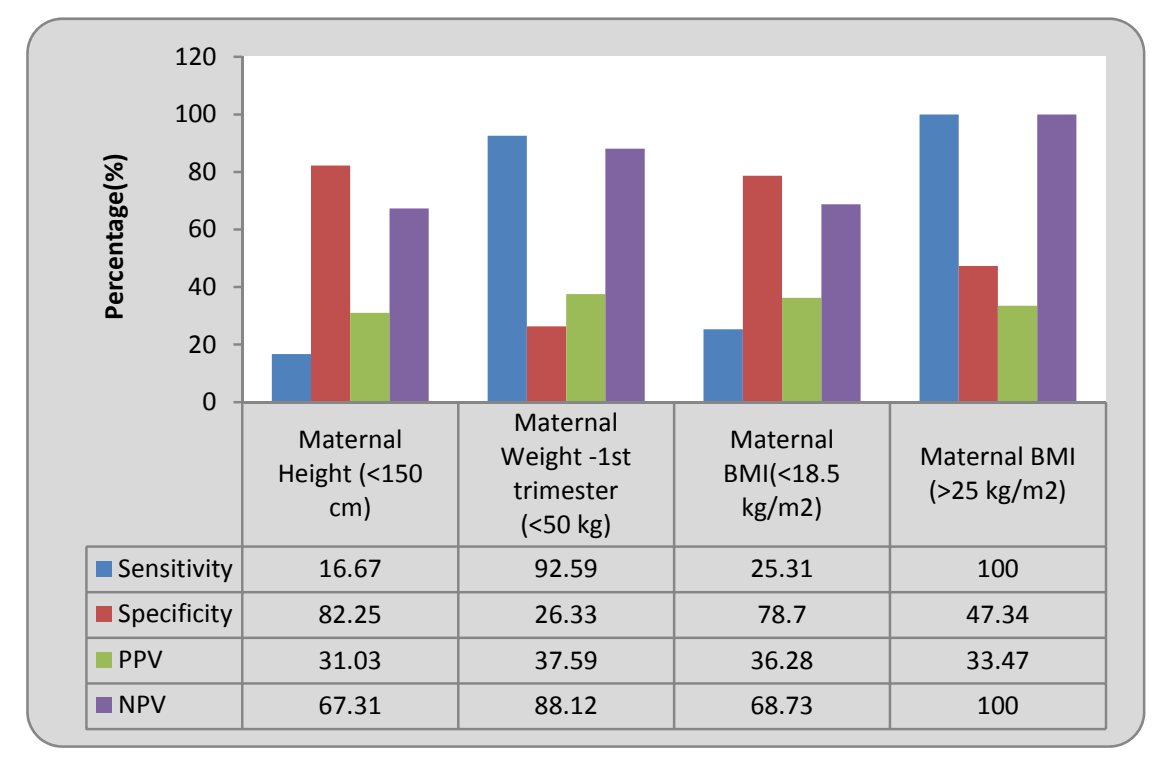

Graph 2 : Predictive ability of maternal anthropometric measures.

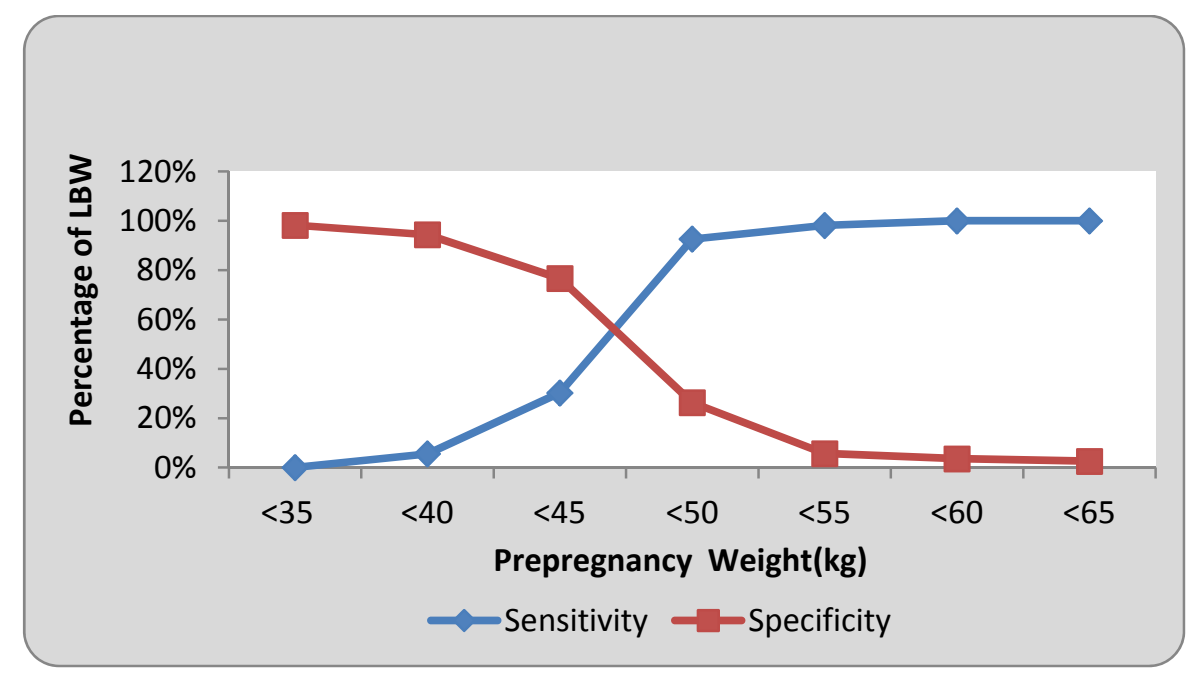

Graph 3: Sensitivity \& Specificity for low birth weight by pre pregnancy weight. 


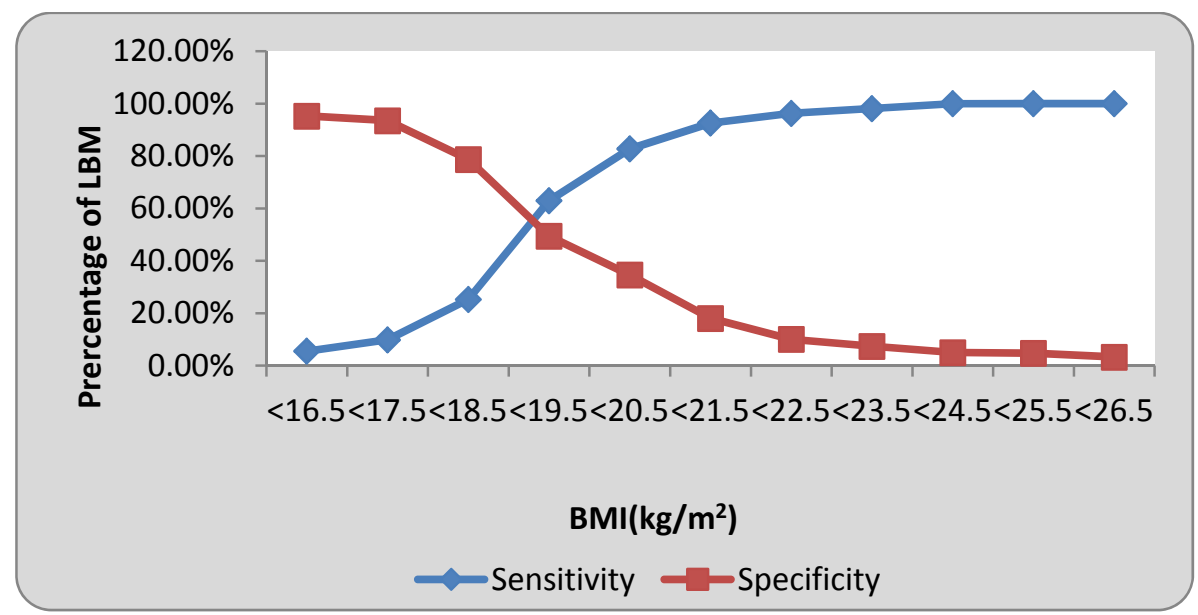

Graph 4: Sensitivity and Specificity for low birth weight by Pre-pregnancy BMI.

\section{Disscussion}

Human fetal growth is characterized by sequential patterns of tissue and organ growth, differentiation and maturation. In early gestation, the major determinant of fetal growth is the fetal genome. But in late pregnancy, environmental, nutritional, and hormonal influences become increasingly important [10]. Several maternal anthropometric and demographic variables like pre-gravid weight, height, body mass index, gestational weight gain, parity and gestational age at delivery independently predict birth weight [11]. The present study examined prepregnancy BMI, maternal anthropometry and neonatal parameters.

The mean maternal pre pregnancy BMI in the study population was $19.74 \pm 2.36$. which was much lower than that found by Jeminusi et al. [12] $\left(27.9 \pm 4.3 \mathrm{~kg} / \mathrm{m}^{2}\right)$ and Koepp et al. [13] $\left(24 \pm 4.3 \mathrm{~kg} / \mathrm{m}^{2}\right)$ but nearer to an Indian study conducted by Kader et al. [14] $\left(21.3 \pm 4.5 \mathrm{~kg} / \mathrm{m}^{2}\right)$. The mean pre-pregnancy Body Mass index was found to be 19.25 $\pm 1.68 \mathrm{~kg} / \mathrm{m}^{2}$ in LBW group and $19.98 \pm 2.60 \mathrm{~kg} / \mathrm{m}^{2}$ in normal birth weight group (difference is statistically significant $\mathrm{z}=3.75, \mathrm{p}=0.001$ ).

Of total 500 women, $113(22.6 \%)$ are underweight $\left(\mathrm{BMI}<18.5 \mathrm{~kg} / \mathrm{m}^{2}\right), 371(74.2 \%)$ had BMI between 18.5-24.9 $\mathrm{kg} / \mathrm{m}^{2}, 8(1.6 \%)$ between $25-29.9 \mathrm{~kg} / \mathrm{m}^{2}$ and $8(1.6 \%)$ were obese with BMI $>30 \mathrm{~kg} / \mathrm{m}^{2}$. This distribution is much different from developed countries wherein less pregnant women have lean weight and more are obese. In the United States of America, for example, $2 \%$ of pregnant women have a BMI $<18.5$ and more than $50 \%$ have a BMI $>25$ (15). In a study done in Canada by Vinturache et al. [15] of the 1996 participants included in the study, 1313 (65.8\%) were normal weight, 427 (23.6\%) were overweight and 211 (10.6\%) were obese from which 31 had BMI $\geq$ $40 \mathrm{~kg} / \mathrm{m}^{2}$. Yekta et al. [16] (2004) in his study on 270 women reported that only half of subjects had normal BMI (19.8-26). However, in a study done by Masho et al. [17] over two-thirds of the study population had normal prepregnancy weight (68.9\%); and $15 \%$ and $6 \%$ were overweight and obese, respectively. In the present study too, more women had normal or low BMI (96.8\%) and very few (3.2\%) were overweight and obese. The population in 
this region falls in low BMI category which does indicate an effect of malnutrition which is chronic in its nature affecting the weight and height of prospective pregnant women and thus the BMI. The malnourishment starts in infancy and progresses through adolescence and adulthood. The study indicates the need for policy based interventions targeting nutrition of adolescent girls to improve the outcome of future generation.

Pre pregnancy BMI is significantly associated with LBW as shown in studies done by Kader et al. (14), Mumbare et al. [18], Nagargoje et al. [19], Dharmalinga et al. [20] and Rafati S et al. [21]. This is consistent with the present study, in which pre pregnancy BMI is positively correlated with birth weight both in LBW and normal birth weight group.(by applying Pearson correlation coefficient $r=0.232$ in LBW group , and $r=0.402$ in normal birth weight group, $\mathrm{p}<0.001$ ). But Ojha et al. [22] did not find significant correlation between BMI and low birth weight.

In a meta-analysis done by Zhangbin Yu et al. [23] 2013, in comparison with a mother with a normal BMI, the results from this analysis revealed that pre-pregnancy underweight increased the risk of SGA (OR, 1.81; 95\% CI, $1.76-1.87 ; P<0.001$ ), in contrast, pre-pregnancy overweight or obesity decreased the risk of LBW in the metaanalysis (OR, 0.83 ; 95\% CI, 0.81-0.84; and OR, $0.81 ; 95 \%$ CI, $0.80-0.83 ; P<0.001)$. According to the Norwegian study pre-pregnant BMI alone is an important predictor of birth weight, the authors reported that for every increase of $1 \mathrm{~kg}$ in pre-pregnancy BMI, there was an increase in birth weight of $25.9 \mathrm{~g}(95 \% \mathrm{CI}, 25.0-26.9)$. For every $1 \mathrm{~kg}$ of maternal weight gain during pregnancy, birth weight increased by $22.4 \mathrm{~g}(95 \% \mathrm{CI}, 21.5-23.3)$. These increases were seen across all six categories of pre-pregnancy BMI (Koepp UM [13]). Offspring birth weight increased with increasing pre-pregnancy maternal BMI and increasing weight change during pregnancy. Similar findings were seen in our study.

Backstrand et al. [24] found that at all periods of pregnancy the best predictors of birth weight were maternal weight and BMI. In pre-pregnancy and in first trimester the BMI had marginally stronger correlations than weight alone. Plots and multiple regression models suggest that most of this effect of BMI is due to weight, with little independent effect of height. Similarly, Ogunyemi [25] et al. showed that prepregnancy BMI was significant predictor of low birth weight. Evidence indicates that women with low pre-pregnancy BMI are more likely to have smaller infants than heavier women, even when their gestational weight gain is the same (Yucel and Cynar et al. [26] 2009). The present study corroborates these findings.

In a study done in China infants born to $27 \%$ of women who were severely underweight before pregnancy (BMI $\leq$ $18.5 \mathrm{~kg} / \mathrm{m}^{2}$ ) were at increased risk for fetal growth deficits associated with infant morbidity. Compared with a normal BMI, being severely underweight was associated with mean ( \pm SEM) reductions of $219 \pm 40 \mathrm{~g}$ in infant birth weight and $6.7 \pm 1.3 \%$ in the birth weight ratio and an $80 \%$ increase in risk of intrauterine growth restriction [odds ratio (OR) $1.8 ; 95 \% \mathrm{CI}: 1.0,3.3 ; P=0.05]$. Bhattacharya also stated that birth weights less than $2,500 \mathrm{~g}$ were more common in underweight women [OR 1.7 (95\% OR 1.2, 2.0)]. Ehrenberg et al. [27] (2003) found the association with LBW at a cut-off point of pre-pregnancy BMI $<19.8 \mathrm{~kg} / \mathrm{m}^{2}$. An Indian study by Bisai [28] showed that cut off value was $<21.5 \mathrm{Kg} / \mathrm{m}^{2}$. In our study cut off value of pre-pregnancy BMI in detecting LBW was $19.5 \mathrm{Kg} / \mathrm{m}^{2}$. 
Hassan et al. [26] in their study found that maternal pre- pregnancy BMI was significantly correlated with neonatal weight, neonatal length, neonatal ponderal index. Mohsen et al. [29] found that maternal pre- pregnancy BMI was positively correlated with neonatal weight, but significantly negatively with neonatal length, neonatal Ponderal index, head circumference, arm circumference and chest circumference in LBW group, while the significance is positive with neonatal Ponderal index, head circumference, arm circumference and chest circumference in normal birth weight group. In our study maternal Pre pregnancy BMI is positively correlated with birth weight, neonatal length, chest circumference, head circumference in both LBW and normal birth weight group and negatively with ponderal index in LBW group and arm circumference in normal birth weight group. Yucel and Cynar also reported that maternal pre gestational BMI was an important factor influencing newborn's birth weight and ponderal index. In a study done by Li et al. [30], when compared to women with pre-pregnancy BMI between 18.5 and 24.0, the odds ratios (ORs) for low birth ponderal index (PI) were 2.34 [95\% confidence interval (CI), 1.24-4.42)] among those with $\mathrm{BMI}<18.5$, respectively, while 2.73 (1.12-6.68) for high birth PI among those with BMI > 24.0.

Causes of low birth weight are complex and interdependent, but the anthropometry of the mother and her nutritional intake are thought to be among the most important [31]. Pre-pregnancy weight and body mass index (BMI) have strong, positive effects on fetal growth, suggesting that energy balance is an important determinant of birth outcomes. The WHO collaborative study on maternal anthropometry and pregnancy outcomes, using data from 111,000 women from across the world reported that mothers in the lowest quartile of pre-pregnancy weight, carried an elevated risk of IUGR and LBW of 2.55 (95\% CI 2.3, 2.7) and 2.38 (95\% CI 2.1, 2.5) respectively, compared to the upper quartile. A study in India reported the odds ratio for LBW among Indian mothers to be three times more in severe chronically energy deficient (CED) low BMI groups when compared to normal BMI groups. Another prospective pregnancy cohort study carried out in Bangalore, India, confirmed that a low maternal weight at baseline is an important predictor of IUGR after controlling for potential confounding variables. Low maternal body weight had an association with higher risk of IUGR of marginal significance (AOR: 1.62; 95\% CI: 0.83, 3.15; $\mathrm{P}=0.09$ ).

BMI is the most efficient screening tool for high- risk mothers during pregnancy. A study in Bengal by Bassi et al. [32] found that, mother's BMI had high sensitivity and more negative predictive power . In our study, Maternal prepregnancy weight below $50 \mathrm{~kg}$ had a high sensitivity of $92.59 \%$ and negative predictive value of $88.12 \%$ with a likelihood ratio of 1.25 for LBW babies, however, the specificity was low. Maternal BMI below $18.5 \mathrm{~kg} / \mathrm{m}^{2}$ had a specificity of 78.70 and likelihood ratio of 1.18 in predicting low birth weight. Maternal BMI above $25 \mathrm{~kg} / \mathrm{m}^{2}$ had $100 \%$ sensitivity and $100 \%$ NPV in detecting LBW babies with a likelihood ratio of 1.05 . The average women seeking care in this area of rural central India has a lean pre-pregnancy weight and low body mass index thus representing the effects of chronic malnourishment in infancy, childhood and adolescence. Thus there is a need to focus on interventional programmes targeting the adolescent population so that the prospective mothers would have appropriate weight and BMI, affecting positively the future generation. 


\section{Conclusion}

Women in the geographic region of the study had low body mass index depicting chronic malnourishment. The main health problem that has emerged from the study is the existence of malnourishment in the obstetric population dating back to poor nutrition in childhood and adolescence finally leading to poor neonatal outcome in the form of high prevalence of low birth weight. The prevalence of maternal obesity was low and there was no macrosomic baby in the study. A BMI below $19.5 \mathrm{~kg} / \mathrm{m}^{2}$ and also above $25 \mathrm{~kg} / \mathrm{m}^{2}$ were good predictors of low birth weight babies. Maternal BMI had a significant association with birth weight, length, head circumference, arm circumference and chest circumference, thus indicating a need to concentrate on public health interventions in the form of nutritional enhancement of girl child in childhood and adolescence and improved pre-conceptional care to obtain a good neonatal outcome. In spite of its limitations, the present study provides interesting findings and important information which can benefit in planning and implementing maternal and child health services in the region.

\section{Limitations}

The present study had a few limitations. Most important was that it was a hospital based study, thus the chances of getting referred cases were high. The majority of women included in the study lived in the surrounding area. The result of this study, therefore may not be completely applicable to women living and delivering their babies in more remote areas of the district.

\section{Acknowledgement}

We acknowledge sincerely the support of faculty and postgraduates of Obstetrics, and administrators of Mahatma Gandhi Institute of Medical Sciences, Sevagram, India and Kasturba Health Society. We also acknowledge the participants of the study

\section{Conflict of Interest}

The authors declare no conflict of interest.

\section{References}

1. Shetty P. Measures of nutritional status from anthropometric survey data (2003).

2. Status IoMSoN, Pregnancy WGd, Intake IoMSoD, Pregnancy NSd. Nutrition during pregnancy: part I, weight gain: part II, nutrient supplements: Natl Academy $\operatorname{Pr}$ (1990).

3. Buschur E, Kim C. Guidelines and interventions for obesity during pregnancy. International Journal of Gynecology and Obstetrics 119 (2012): 6-10.

4. Carnero AM, Mejía CR, García PJ. Rate of gestational weight gain, pre-pregnancy body mass index and preterm birth subtypes: a retrospective cohort study from Peru. BJOG: An International Journal of Obstetrics and Gynaecology 119 (2012): 924-935.

5. Durie DE, Thornburg LL, Glantz JC. Effect of second-trimester and third-trimester rate of gestational weight gain on maternal and neonatal outcomes. Obstetrics and gynecology 118 (2011): 569-575. 
6. Schieve LA, Cogswell ME, Scanlon KS, et al. Prepregnancy body mass index and pregnancy weight gain: associations with preterm delivery. Obstetrics and Gynecology 96 (2000): 194-200.

7. Gueri M, Jutsum P, Sorhaindo B. Anthropometric assessment of nutritional status in pregnant women: a reference table of weight-for-height by week of pregnancy. The American journal of clinical nutrition 35 (1982): 609-616.

8. Organization WH. Obesity: preventing and managing the global epidemic: World Health Organization (2000).

9. Tan K. Appropriate body-mass index for Asian populations and its implications for policy and intervention strategies. The Lancet 363 (2004): 157-163.

10. Holmes RP, Holly JM, Soothill PW. A prospective study of maternal serum insulin-like growth factor-I in pregnancies with appropriately grown or growth restricted fetuses. Br J Obstet Gynaecol 105 (1998): 12731278.

11. Catalano PM, Drago NM, Amini SB. Maternal carbohydrate metabolism and its relationship to fetal growth and body composition. Am J Obstet Gynecol 172 (1995): 1464-1470.

12. Jeminusi O, Sholeye O. Maternal anthropometry in rural and urban areas of Ogun-East senatorial district, Nigeria: A comparative study. International Journal of Nutrition and Metabolism 7 (2015): 39-45.

13. Stamnes Koepp UM, Frost Andersen L, Dahl-Joergensen K, et al. Maternal pre-pregnant body mass index, maternal weight change and offspring birthweight. Acta obstetricia et gynecologica Scandinavica 91 (2012): 243-249.

14. Kader M, Perera NKP. Socio-economic and nutritional determinants of low birth weight in India. North American journal of medical sciences 6 (2014): 302.

15. Vinturache AE, McDonald S, Slater D, et al. Perinatal outcomes of maternal overweight and obesity in term infants: a population-based cohort study in Canada. Scientific reports (2015): 5.

16. Yekta Z, Ayatollahi H, Porali R, et al. The effect of pre-pregnancy body mass index and gestational weight gain on pregnancy outcomes in urban care settings in Urmia-Iran. BMC Pregnancy and Childbirth 6 (2006): 15 .

17. Masho SW, Bishop DL, Munn M. Pre-pregnancy BMI and weight gain: where is the tipping point for preterm birth? BMC pregnancy and childbirth 13 (2013): 120.

18. Mumbare SS, Maindarkar G, Darade R, et al. Maternal risk factors associated with term low birth weight neonates: a matched-pair case control study. Indian pediatrics 49 (2012): 25-28.

19. Nagargoje M, Chaudhary S, Deshmukh J, et al. A Case Control Study of Risk Factors for Low Birth Weight in Nagpur City of Maharashtra. Indian Journal of Community Health 22 (2011): 4-7.

20. Dharmalingam A, Navaneetham K, Krishnakumar C. Nutritional status of mothers and low birth weight in India. Maternal and child health journal 14 (2010): 290-298.

21. Rafati S, Borna H, Akhavirad MB, et al. Maternal determinants of giving birth to low-birth-weight neonates. Archives of Iranian Medicine 8 (2005): 277-281.

22. Ojha N, Malla D. Low birth weight at term: relationship with maternal anthropometry. Journal of Nepal Medical Association 46 (2007). 
23. Yu Z, Han S, Zhu J, et al. Pre-pregnancy body mass index in relation to infant birth weight and offspring overweight/obesity: a systematic review and meta-analysis. PloS one 8 (2013): e61627.

24. Backstrand J. Annex: Maternal anthropometry as a risk predictor of pregnancy outcome: the Nutrition CRSP in Mexico. Bulletin of the World Health Organization 73 (1995): 96.

25. Ogunyemi D, Hullett S, Leeper J, et al. Prepregnancy body mass index, weight gain during pregnancy, and perinatal outcome in a rural black population. Journal of Maternal-Fetal and Neonatal Medicine 7 (1998): 190-193.

26. Yucel O, Cinar ND. Maternal risk factors affecting Newborn parameters. Pak J MedSci 25 (2009): 386.

27. Ehrenberg HM, Dierker L, Milluzzi C, et al. Low maternal weight, failure to thrive in pregnancy, and adverse pregnancy outcomes. American journal of obstetrics and gynecology 189 (2003): 1726-1730.

28. Bisai S. Report of the IDSK Development Research: Relationship of maternal anthropometry and birth outcome among Bengalis of Kolkata, India. IDSK (Institute of Development Studies Kolkata) West Bengal, India (2004).

29. Mohsen MA, Wafay HA. Influence of maternal anthropometric measurements and serum biochemical nutritional indicators on fetal growth. J Med Sci 7(2007): 1330-1334.

30. Li Y, Chen X, Chen S, et al. A cohort study on the impacts of pre-pregnancy maternal body mass index, gestational weight gain on neonate birth status and perinatal outcomes in Fujian province. Zhonghua liu xing bing xue za zhi= Zhonghua liuxingbingxue zazhi 35 (2014): 635-640.

31. Muthayya S. Maternal nutrition \& low birth weight-what is really important. Indian J Med Res 130 (2009): 600-608.

32. Bisai S, Mahalanabis D, Sen A, et al. Maternal early second trimester pregnancy weight in relation to birth outcome among Bengalee Hindus of Kolkata, India. Annals of human biology 34 (2007): 91-101.

Citation: Surekha Tayade, Ritu Singh, Jaya Kore, Neha Gangane. Maternal Anthropometric measurements, Pre-pregnancy Body Mass Index, and Fetal Growth Parameters - A Rural Experience. Obstetrics and Gynecology Research 1 (2018): 051-064.

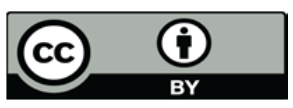

This article is an open access article distributed under the terms and conditions of the

Creative Commons Attribution (CC-BY) license 4.0 